\title{
COMMENTARY
}

\section{Moving a National Preceptor Development Platform from Design to Reality}

Angela Brownfield, PharmD, ${ }^{\mathrm{a}}$ Charlene R. Williams, PharmD, ${ }^{\mathrm{b}}$ Craig D. Cox, PharmD, ${ }^{\mathrm{c}}$ Lindsay E. Davis, PharmD, ${ }^{\mathrm{d}}$ Seena L. Haines, PharmD, ${ }^{\mathrm{e}}$ Kerry Anne Rambaran, PharmD, ${ }^{\mathrm{f}}$ Melissa Ruble, PharmD, ${ }^{\mathrm{g}}$ Mary Douglass Smith, PharmD ${ }^{\text {h }}$

${ }^{\text {a }}$ University of Missouri-Kansas City, School of Pharmacy, Columbia, Missouri

${ }^{\mathrm{b}}$ University of North Carolina, Eshelman School of Pharmacy, Asheville, North Carolina

${ }^{\mathrm{c}}$ Texas Tech University Health Sciences Center, Jerry H. Hodge School of Pharmacy, Lubbock, Texas

${ }^{\mathrm{d}}$ Midwestern University, College of Pharmacy. Glendale, Arizona

${ }^{\mathrm{e}}$ University of Mississippi, School of Pharmacy, Jackson, Mississippi

${ }^{\mathrm{f}}$ Scripps Mercy Hospital, San Diego, California

${ }^{g}$ University of South Florida, Taneja College of Pharmacy, Tampa, Florida

${ }^{\text {h }}$ Presbyterian College, School of Pharmacy, Clinton, South Carolina

Corresponding Author: Angela Brownfield, University of Missouri-Kansas City, School of Pharmacy, Columbia MO 65211. Tel: 573-884-9968. Email: brownfielda@umkc.edu.

Submitted February 15, 2021; accepted September 27, 2021; ePublished October 2021

Keywords: preceptor development, national, platform, self-assessment 


\section{INTRODUCTION}

Preceptor development is critical to the success of experiential rotations. Experiential learning comprises at least $30 \%$ of the Doctor of Pharmacy curricula in the United States and is the core component of residency training. As both volunteer and faculty instructors are responsible for training learners in a real-world environment, professional development is fundamental to the quality of these experiential rotations. ${ }^{1-3}$ Although accreditation standards on preceptor training exist, specific guidance on the quantity and quality of these experiences is currently limited..$^{1-3}$ Thus, schools/colleges of pharmacy (S/COP) vary widely in resources allocated to these efforts and types of professional development opportunities they offer. ${ }^{4}$ Preceptor development has been identified as one of the primary challenges facing experiential offices around the country, and surveys have identified multiple concerns, including the availability of resources to deliver such training. ${ }^{5-7}$ Additional barriers have included lack of incentives to participate, inability to track completion, and the shortage of offerings for personalized preceptor development. ${ }^{4}$

The American Association of Colleges of Pharmacy (AACP) recognizes a need for a more collaborative approach to preceptor development that encompasses the expertise and resources of S/COP and professional organizations across the country. AACP has put an increased emphasis on preceptors over the past decade, and preceptor development has been the focus of multiple recent AACP Professional Affairs Committees. ${ }^{8-10}$ Membership opportunities for preceptors have expanded, along with the opportunity to be recognized as a Master Preceptor by the Association. ${ }^{8}$ In addition, the AACP Experiential Education (EE) Section has a standing committee focused on identifying training resources for preceptors each year to assist in their development. As a result of these efforts, the need to formalize a development process for preceptors to ensure they are prepared to successfully train future students and residents was deemed critical.

Given that a preferred delivery mode and medium for development resources are not currently identified in the literature, S/COP are pressed to offer a variety of delivery media to satisfy diverse audience needs. ${ }^{11}$ Although many institutions offer a myriad of programming options, a formalized process that intentionally guides preceptors on an individualized journey to identify their developmental needs and complete programs to address those needs appears to be limited. Therefore, development of a national platform that encourages a self-directed approach, provides motivation for engagement, and offers a diverse array of resources to target a preceptor's learning needs is warranted. Establishing this platform for preceptor development is critical to success. The 2019-2020 AACP Council of Faculties (COF) created the Task Force on Preceptor Engagement and Development to achieve several goals. First, to identify the core elements of a platform that would facilitate preceptor development. Second, to conceptualize how these elements could be incorporated into the design of an online platform. Third, to collect insight from key stakeholders on strategies that would help promote future engagement with such a platform. The Task Force's efforts to address these key areas has been outlined below. We challenge readers to consider whether we are now positioned to move to the formal development stage to bring these proposed design strategies to life. We believe that we are.

\section{DISCUSSION \\ Strategic Process}

Members assigned to this Task Force had vast experience in experiential education (range 5-21 years, mean 13 years as both a preceptor and administrator of an experiential program) and contributed to preceptor development strategies at their own institutions. In July 2019, the group met with the Chair Liaison during the AACP Annual Meeting in Chicago, Illinois to review charges and expected deliverables. The committee was divided into two subgroups. One group focused on developing strategies to promote preceptor engagement with the platform, including a process for entry into the site. The second group was charged with identifying the core features the site would offer its users. The Chair was a part of each workgroup to ensure clear communication and foster a consistent vision. In January 2020, both subgroups reconvened to review and combine their work. At this time, core elements of the national platform were established and strategies for development were discussed. In addition, the Task Force worked collaboratively with the AACP Experiential Education Section Preceptor Development Resources Task Force to garner feedback regarding platform design. The final recommendations of the COF Task Force were included in a comprehensive report that was provided to the AACP Board of Directors.

\section{Unique Design}

The Task Force unanimously agreed the platform should focus on Continuing Professional Development (CPD), include Specific Measurable Achievable Relevant Time-Bound (SMART) goals, and encourage the opportunity to engage in a Self-Directed Assessment Seeking (SDAS) approach. ${ }^{12-15}$ CPD emphasizes self-assessment and self-reflection in the cycle of identifying relevant learning needs and goals, implementing an individualized development plan to accomplish goals, and evaluating the effectiveness of the plan. ${ }^{12}$ SDAS is the strategy of seeking external sources of feedback and 
assessment to direct performance improvement in addition to focusing on self-reflection. ${ }^{15}$ A desirable outcome of the SDAS approach is the development of a "coherent self-awareness of one's strengths and weaknesses" that spurs behavioral change. ${ }^{15}$ The unique design of this platform focusses on, offers, and promotes direct self-assessment opportunities while allowing the trainee to bring in additional assessments (eg, peer, student), if desired. It also allows users to choose their own journey and proceed at their own pace. Preceptors can move from point A to point B in a personalized manner. For example, preceptors may choose to omit formal assessments and simply proceed with activities of interest.

The envisioned platform would also offer and illustrate the concept that precepting is a lifelong journey. As learners, preceptors could potentially rejoin novice preceptors as mentors/guides for "mastered topics". In addition, the design would consider precepting from a holistic perspective to ensure relevance to a broad audience. Ultimately, the impact of the platform would hinge upon its ability to efficiently and effectively engage preceptors from nascent to seasoned with relevant, timely, convenient, and robust continuing professional development content.

The proposed core elements were placed into four main categories: overall considerations, design, content, and engagement (Table 1). The evidence-based framework for the platform was supported by a series of publications focused on a similar Canadian initiative. That initiative had led to development of a design for a national preceptor development platform along with a competency framework to guide its use. ${ }^{11,16,17}$ Additional guiding principles also came from the work of the 2017-2018 AACP Professional Affairs Standing Committee as well as the work of Boyle and colleagues on developing an academy of preceptors. ${ }^{10,18}$

Figure 1 highlights the needs assessment, vision, suggested action, and potential outcome of the platform design. Preceptor interest and continued engagement were determined to be pivotal pieces of the platform. The visual impact of the "journey" of a preceptor's development was vital as well. One suggestion was that characters or avatars would travel through various development scenarios adding a "gaming" aspect to personalize the experience. The platform would also entail the use of simple, automated options to harness the power of technology through digital behavioral change interventions.

\section{Support from Colleagues}

Perspectives from the AACP EE Section were critical in confirming the direction and core elements of the platform for the Task Force. A call was sent out in April of 2020 to EE section members to attend a one-hour focus group over Zoom (Zoom Video Communications Inc., 2016). Approximately 40 individuals attended the session, representing S/COP across the country, including both private and public institutions. The first draft of the Task Force report was shared with attendees prior to this meeting. Five key questions were posed involving the following themes: elements that would facilitate engagement, unique and/or essential features that would promote success, potential challenges, and considerations for sustainability. Several pivotal themes emerged from the session and directly aligned with the Task Force's goal for the platform: recognition for completed work, elements of sustainability, centralization of the platform, individualization of learning, and advertisement and engagement tools. Overall, feedback from the focus group reaffirmed the ideas of the Task Force and provided further support for its development.

\section{Potential Challenges and Needed Resources for Development}

As with any new program, there will be anticipated challenges. Logistically creating and sustaining such a platform will be both costly and time consuming. More importantly, it will require fostering relationships and collaborations with other pharmacy organizations, effective marketing and advertising to garner preceptor awareness, and a concentrated effort to access technology resources. In addition, there is the challenge of providing constant momentum to motivate users to repeatedly engage with the platform as well as the personal availability of time outside of other workload responsibilities for user engagement.

With respect to needed resources, the Task Force felt identification of funding for the requisite information technology (IT) infrastructure was crucial. Possible options included integration with AACP's website, a standalone platform, or a marketplace platform. In addition, it would be imperative to secure and fund long-term, dedicated IT support to manage website content (eg, links to external content), maintain database security, provide site/user analytics, and address user technology queries.

Creation of a leadership model for sustainability was considered important as well. The Task Force recommended that a dedicated AACP staff member be assigned to provide institutional and historical knowledge. The Task Force further recommended that the AACP EE Section be offered programmatic content oversight and serve as the liaison for other AACP Sections and other pharmacy organizations. In addition, the Task Force recognized the value of students, residents, and fellows in the development and ongoing evolution of the project. 
Resources needed for the curation of content were also deemed to be vital. The AACP EE Section could form a committee that would be tasked with identifying, organizing, and mapping content to overall established outcomes. The structure would include essential members with individual expertise, an AACP liaison, and a staggered two-year term to retain historical information while allowing for an influx of fresh ideas. Additionally, AACP could collaborate with other organizations including the American College of Clinical Pharmacy (ACCP), the American Pharmacists Association (APhA), American Society of Health-System Pharmacists (ASHP), and CEImpact to link to existing preceptor development programs.

\section{A Call to the Academy}

Professional preceptor development is fundamental to the success and quality of experiential training. AACP could serve as a visionary steward for the development of a comprehensive, structured, and collaborative approach to national preceptor development to facilitate meaningful behavioral change. Although many institutions offer a myriad of programming options for their preceptors, a formalized platform that intentionally identifies individual developmental needs and then provides numerous options in one, central location to address those needs is optimal. We have conceptualized the design and have a clear outlook, yet we are at a critical point. To bring these design strategies to reality, we must gather additional feedback from stakeholders who would be involved with both the development and utilization of the platform, create a detailed business plan, and present this data to AACP leadership to help address important feasibility and support considerations. These steps will ultimately impact the timeline and availability to preceptors. However, as a plea to move forward, we seek genuine responses from the academy to the following inquiries: Have we convinced you that we are ready for this journey? Do we have what we need to move to the development stage? Is it time to take the leap? Readers are encouraged to provide a response to this commentary.

\section{CONCLUSION}

To our knowledge, this would be the first preceptor development platform that aims to offer diverse content and engagement opportunities as well as a self-directed approach. Although there will never be a "perfect" time to initiate such an endeavor, it seems demand has been present for years. This Task Force believes it is critical to train the upcoming workforce for challenges, demands, and the changing landscapes of the profession while aiding S/COP in the provision of professional development opportunities. By implementing the platform now, we would provide a streamlined, navigable site for preceptors to sharpen their skills, thus leading to an enhanced quality of experiential rotations.

\section{ACKNOWLEDGMENTS}

The authors would like to acknowledge the collective work of the 2019-20 AACP Experiential Education Section Preceptor Development Resources Task Force along with all members of the 2019-20 AACP Council of Faculties Preceptor Engagement and Development Task Force for contributing feedback for the platform's design. 


\section{REFERENCES}

1. Accreditation Council for Pharmacy Education. Accreditation standards and key elements for the professional program in pharmacy leading to the doctor of pharmacy degree (Standards 2016). https://www.acpeaccredit.org/pdf/Standards2016FINAL.pdf. Accessed June 9, 2021.

2. Accreditation Council for Pharmacy Education. Guidance for the accreditation standards and key elements for the professional program in pharmacy leading to the doctor of pharmacy degree. (Guidance for Standards 2016). https://www.acpe-accredit.org/pdf/GuidanceforStandards2016FINAL.pdf. Accessed June 9, 2021.

3. American Society of Health-System Pharmacists. Guidance document for the ASHP accreditation standard for postgraduate year one (PGY1) pharmacy residency programs. https://www.ashp.org/-/media/assets/professionaldevelopment/residencies/docs/guidance-document-PGY1standards.ashx?la=en\&hash=20D275DC632B78E92626D7233DF52747279FE820. Accessed June 9, 2021.

4. O'Sullivan TA, Cox CD, Darbishire P, et al. The status and adequacy of preceptor orientation and development programs in US Pharmacy Schools. Am J Pharm Educ 2020;84(2):Article 7540.

5. Danielson J, Eccles D, Kwasnik A, Craddick K, Heinz AK, Harralson AF. Status of pharmacy practice experiences education programs. Am J Pharm Educ. 2014;78(4):Article 72.

6. Danielson J, Craddick K, Eccles D, Kwasnik A, O’Sullivan TA. Challenges facing pharmacy experiential education: a qualitative analysis of common concerns. Am J Pharm Educ. 2015;79(1):Article 6.

7. Devine PS, Darbishire PL. National trends in IPPE programs at US schools of pharmacy from 2008-2013. Am J Pharm Educ. 2015;79(3):Article 39.

8. Harris BJ, Butler M, Cardello E, et al. The report of the 2011-2012 AACP Professional Affairs Standing Committee: addressing the teaching excellence of volunteer pharmacy preceptors. Am J Pharm Educ. 2012;76(6):Article S4.

9. Chair KW, Aistrope DS, Auslie J et al. The report of the 2016-2017 Professional Affairs Standing Committee: formally embracing preceptors in the academy-the time has come. Am J Pharm Educ. 2017;81(9):Article S16.

10. Vos SS, Brown MM, Cardello EA, et al. The report of the 2017-2018 Professional Affairs Standing Committee: the development of the preceptor self-assessment tool for entrustable professional activities for new graduates. $A m J$ Pharm Educ. 2018;82(7):Article 7162.

11. Mulherin K, Walter S, Cox CD. National preceptor development program (PDP): influential evidence and theory. The first of a 3-part series. Curr Pharm Teach Learn. 2018;10(3):255-266.

12. Accreditation Council for Pharmacy Education. Guidance on continuing professional development (CPD) for the profession of pharmacy. https://www.acpe-accredit.org/pdf/CPDGuidance\%20ProfessionPharmacyJan2015.pdf. Accessed June 9, 2021.

13. Janke KK, Tofade T. Making a curricular commitment to continuing professional development in Doctor of Pharmacy programs. Am J Pharm Educ. 2015;79(8):Article 112.

14. Tofade T, Kim J, Lebovitz L, et al. Introduction of a continuing professional development tool for preceptors: lessons learned. J Pharm Pract. 2015;28(2):212-219.

15. Eva KW, Regehr G. "I'll never play professional football" and other fallacies of self-assessment. J Contin Educ Health Prof. 2008;28(1):14-19.

16. Walter S, Mulherin K, Cox CD. A preceptor competency framework for pharmacists. Part 2 of a 3-part series. Curr Pharm Teach Learn. 2018;10(3):402-410.

17. Cox CD, Mulherin K, Water S. National preceptor development program (PDP) prototype. The third of a 3-part series. Curr Pharm Teach Learn. 2018;10(3):298-306.

18. Boyle CJ, Morgan JA, Layson-Wolf C, et al. Developing and implementing an Academy of Preceptors. Am J Pharm Educ. 2009;73:Article 34. 


Assess need for a comprehensive, structured, collaborative approach to preceptor development
- Experiential training comprises at least $30 \%$ of Doctor of Pharmacy curricula

- AACP could steward the development of an online platform to meet this need

Envision an online platform with content meeting the continuous development needs of experiential preceptors

- Content should be available that meets the needs of all pharmacy preceptors (beginner, intermediate, advanced)

- Content should be easily accessible, robust, and comprehensive

- Content should be thoughtfully curated encompassing various modes of delivery (readings, webinars, podcasts, videos)

Develop a platform allowing a "choose your own journey" pathway for preceptors to self-select development opportunities

- Platform should allow flexibility of learning opportunities to meet the unique needs and interests of pharmacy preceptors

- Platform should offer digital behavior change interventions alongside networking and mentorship opportunities

- Platform should track preceptor progress

Individualized continuous professional development using a self-directed approach

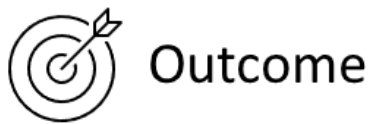

- Engagement with the platform facilitates meaningful behavior change using the self-directed approach including mechanisms for self-reflection, networking, and mentorship

- Preceptor achievement could be recognized through website spotlights, certificates, and/or credentialing 
Table 1. Considerations for Design of a National Preceptor Development Platform

Category

Overall

Considerations

Content

Engagement

\section{Description}

Need for stakeholder (ie, preceptors, experiential administrators, organizations) feedback at various stages of prototype development

Collaboration with pharmacy and other health professional organizations

Selection of preceptor competency framework as foundation to individualized development

Curation of preceptor development programs based on categories (ie cost, continuing education availability, beginner vs. advanced, program duration)

Professional graphic artist to design user friendly, engaging, and visually appealing site

Site navigation to allow for either a "guided" or "choose your own adventure" journey

Utilization of icons representing interactive content and resources available from site

Notification of "new" or "time sensitive" content

Link to phone application to provide versatility for users

Reporting mechanism to create personalized user, individual college/school, and association level reports to aide in tracking of accreditation requirements

Utilization of a SDAS approach to support preceptor growth and development

Documentation of continuing professional development process for individual users

Availability of a diversity of mediums (eg, webinars, podcasts, videos, articles, etc.)

Preceptor spotlights (highlight preceptor accomplishments)

Preceptor blogs (interactive discussion between preceptors and experts)

Online learning communities (preceptors with shared interest and expertise)

Mentoring opportunities (preceptors self-select mentor(s) from expert profile)

Frequently asked questions

Opportunity for advertisements to promote preceptor development programming

Branded site name for "top search results" from Google and other common search engines

"Example" navigation paths to support learning based on self-identified goals and needs

Opportunity to enter and navigate site with personal interests and goals

Opportunity to earn badges, certificates, or credentials

Mechanism for reminders, updates, or alerts to users to encourage re-entry to platform

Registry of experiential leaders to identify individuals to develop content, serve as mentor, monitor blogs, facilitate online community discussion, etc.

Addition of gaming" aspects to personalize the experience

Use of social media (eg, Facebook, Twitter, Instagram, etc.) to promote site

SDAS = self-directed assessment seeking 